\title{
Stigma Towards Mental Illness at an Academic Tertiary Care Center in Lebanon
}

\author{
Samer El Hayek ${ }^{1} \cdot$ Michele Cherro $^{1} \cdot$ Alaeddine El Alayli $^{1} \cdot$ Rawad El Hayek $^{1} \cdot$ Elias Ghossoub $^{1}$ (I)
}

Received: 5 March 2021 / Accepted: 7 July 2021 / Published online: 20 July 2021

(C) Academic Psychiatry 2021

\begin{abstract}
Objective Individuals with mental illness may fall victim to stigma. In this cross-sectional study, the authors aimed to explore correlates of stigma towards mental health in a Lebanese private university and its associated tertiary medical center.

Methods The authors surveyed students, staff, and faculty at the American University of Beirut and its associated medical center. They assessed stigmatizing behaviors via the Reported and Intended Behavior Scale (RIBS), perceived stigma via the Perceived Devaluation and Discrimination Scale (PDDS), and attitudes towards collaborating with mental health professionals via the Doctors' Attitudes toward Collaborative Care for Mental Health (DACC-MH).

Results A total of 270 participants (response rate of $18 \%$ ) provided their responses. The mean scores on the RIBS and PDDS were $15.26 \pm 4.75$ and $32.25 \pm 2.70$, respectively. Participants who had higher scores on RIBS were more likely to be younger than 25 years of age $(\mathrm{OR}=1.869 ; p=0.026)$, to have a history of mental illness $(\mathrm{OR}=2.657 ; p=0.003)$, and to interact with individuals with a psychiatric disorder $(\mathrm{OR}=2.287 ; p=0.028)$.

Conclusions Results show a mixed pattern of stigmatizing behaviors and perceptions towards mental illness. This highlights the need for mental health awareness campaigns and interventions in the country.
\end{abstract}

Keywords Mental illness $\cdot$ Stigma $\cdot$ Lebanon

Stigma is a "deeply discrediting" attribute that reduces one "from a whole and usual person to a tainted discounted one" [1]. It is a dangerous, multifaceted construct related to a set of negative beliefs that a society has towards a particular topic. It usually leads to negative consequences, including separation, loss of status, and discrimination [2].

Individuals with mental illness may be affected by stigma. They typically experience shame and marginalization secondary to their diagnosis and often describe the repercussions of mental health stigma as worse than those of the illness itself [3]. The stigma they endure is shown to impact their social lives, relationships, professional careers, and psychological wellbeing [3].

Stigma towards mental illness represents a worldwide public health crisis, with cultural differences contributing to global variations in the profile of stigma [4]. In the Arab world, mental illness has been reported as "shameful" and an "embarrassment" [5]. This typically translates into individuals

Elias Ghossoub

elias.ghossoub@gmail.com

1 American University of Beirut, Beirut, Lebanon being reluctant to seek professional care [6]. In Lebanon, the notion of mental illness has been conventionally appended to "insanity" or "majnoun" in Arabic [7]. Stigma has also been empowered by a lack of awareness and knowledge, and fueled by subcultural beliefs associating mental illness with paranormal entities such as Jinn and the Evil Eye [6]. These views have been shown to be endorsed by the general community, religious figures, and university students [8-10].

To our knowledge, no previous study assessed the attitudes of medical or academic personnel towards mental illness in Lebanon. Also, no study compared attitudes between medical students, nurses, and doctors in this setting. We therefore aimed to explore stigma towards mental health in a Lebanese private university and its associated tertiary medical center.

\section{Methods}

\section{Study Design and Sample}

This cross-sectional study was conducted between February and March 2020. A total of 1,500 individuals from the 
American University of Beirut were invited to participate in the study. Faculty, staff, and students (undergraduate, graduate, or medical students) at the academic setting as well as faculty and staff (including medical doctors, residents, nurses, psychologists, pharmacists, nutritionists, occupational therapists, physiotherapists, case managers, and social workers among others) at the hospital were included in the study. We excluded university alumni from the study.

\section{Sample Size Calculation}

In a recently published study, Abi Doumit et al. found that $67.8 \%$ of Lebanese have a high score of public stigma towards mental illness [10]. Assuming a type I error of 5\%, a significance level at $p<0.05$, and an absolute error or precision of $5 \%$, the minimum sample size required to replicate this analysis was 171 participants per group (5 groups being nonmedical students, medical students, nurses, staff at the academic setting, and residents and faculty members at the hospital). Considering a $50 \%$ response rate, a sample size of 300 participants per group (1,500 in total) was required. Accordingly, 1,500 personnel at the American University of Beirut community received the electronic questionnaire via their e-mails.

Between February and March 2020, we invited participants to fill an online self-administered questionnaire via LimeSurvey, an online survey application. We informed participants about the study, its purpose, and inclusion criteria. Those willing to participate were required to read and accept an online consent form. We sent three reminders at one-week intervals to maximize the efficiency of our recruitment. A total of 328 individuals participated in the study. We included 270 participants with complete responses in the final data analysis achieving, therefore, a response rate of $18 \%$.

\section{Ethical Approval}

The study received approval from the Institutional Review Board of the American University of Beirut (ID SBS-20190485). For privacy and confidentiality, the researchers were blinded to the list of emails of participants and all data were completely de-identified.

\section{Questionnaire}

The questionnaire was in English and included 40 questions, divided into four sections: Sociodemographic and personal data, Reported and Intended Behavior Scale (RIBS), Perceived Devaluation and Discrimination Scale (PDDS), and Doctors' Attitudes toward Collaborative Care for Mental Health (DACC-MH).

In addition to providing basic sociodemographic information, participants were asked to indicate their current status/ role at the American University of Beirut. Moreover, they were asked to answer "yes" or "no" to prompts about their mental health status: "have you ever suffered from a mental illness?", "have you ever been in contact with a mental health professional?", "have you ever taken a prescribed psychotropic medication?", and "do you have a family member with a mental illness?" Lastly, they were asked to specify if they were "comfortable" or "uncomfortable" about disclosing their mental health problems to family/friends and coworkers/colleagues. The option of answering "prefer not to disclose" was possible for all questions in this part.

The RIBS is an eight-item scale that measures mental health stigma-related behavior. The original version is psychometrically robust with strong internal consistency $(\alpha=$ $0.85)$ and test-retest reliability $(r=0.75)$. It includes two sections of four items each. The first group calculates the prevalence of behaviors reported in the past or present experiences regarding the following areas: live with, work with, live nearby, or have a relationship with a person with a mental health problem. Each item is coded as "yes," "no," or "do not know." The second group of items focuses on future intentions to establish contact with people with a mental health problem in the same areas as described above. Each item is coded on an ordinal scale ( $1=$ disagree strongly to $5=$ agree strongly). "Do not know" is coded as neutral. Higher scores correspond to a greater willingness to interact with people with mental illness [11]. In our study, we calculated the average score for each participant. We then created a dichotomous variable to categorize respondents according to their behaviors and attitudes towards individuals with mental illness. A respondent was classified in the Low (or negative) category if they had an average score of 1 to 3 , indicating that the respondent mostly endorsed mental health stigma-related behaviors. Alternatively, a respondent was classified in the High (or positive) category if they averaged a score of 3.1 to 5 , indicating that, overall, the respondent did not endorse mental health stigma-related behaviors.

The PDDS is a twelve-item scale that measures the extent to which a person believes that most people will devalue or discriminate against someone with a mental illness. Each item is rated on a Likert scale ranging from 1 (strongly disagree) to 4 (strongly agree), yielding a total score ranging from 12 to 48 . Higher scores indicate greater perceived public stigma and discrimination related to mental illness. The prevalence of high perceived stigma is defined as an item mean score of 2.5 or higher on the mean aggregated scale score (this criterion represents the "midpoint" on the 1-4 item scale). Participants scoring greater than or equal to the mean score of 2.5 are considered to have "high perceived stigma" and those scoring below 2.5 are considered to have "low perceived stigma" [12].

The DACC-MH is an eight-item scale that measures the readiness of doctors to engage in collaborative mental health care. It assesses two core components of collaborative mental 
health care programs: physicians' attitudes towards managing mental health problems and towards consulting with psychiatrists. Each item is coded as "agree" or "disagree," which are considered as positive and negative responses, respectively. However, for the fourth and eighth items, "disagree" is considered a positive response. The score for each participant is generated by counting the positive responses. Therefore, the minimal and maximal scores range between zero and eight, meaning the most negative and the most positive attitudes, respectively [13]. Only healthcare professionals at the hospital were allowed to fill out the DACC-MH.

\section{Statistical Analysis}

We summarized descriptive statistics by presenting numbers and percentages for categorical variables and means with standard deviations for continuous variables. We assessed the associations between the outcomes (RIBS and PDDS) and specific sociodemographic and personal data using the Pearson chi-square test or Fisher's exact test, as appropriate. We excluded entries that had "prefer not to disclose" as an answer for the sociodemographic data or "non-binary" for the gender question from the bivariate analysis. We dichotomized participants' role by institutional affiliation (university or hospital) or status at the hospital (medical students versus nurses, residents, and attendings). We also grouped participants under "sought health" if they answered yes to at least one of the following: "have you ever been in contact with a mental health professional?" or "have you ever taken a prescribed psychotropic medication?" In addition, we considered as having "social interaction" with an individual with mental illness if they answered yes to at least one of the following: "are you currently living/working with or have you ever lived/worked with someone with a mental health problem?" or "do you currently have or have you ever had a neighbor/close friend with a mental health problem?" Finally, we carried out a multivariate stepwise logistic regression to identify the predictors of RIBS. We also did another logistic regression analysis restricted to the hospital setting to shed light on the difference between medical students and other hospital professionals. We presented the results as adjusted odds ratios (aOR) with $95 \%$ confidence intervals (CI). We used a $p$-value of less than 0.05 to indicate statistical significance. We employed IBM SPSS statistical software for Windows version 22 for the analysis [14].

\section{Results}

\section{Sociodemographic Characteristics of Participants}

A total of 270 participants provided complete responses to the questionnaire. Almost half (51.5\%) were young adults aged between 18 and 25 years. Most participants were women
$(62.2 \%)$ and carried the Lebanese nationality $(87.0 \%)$. Approximately half of the sample consisted of students from non-medical $(17.4 \%)$ and medical $(39.3 \%)$ backgrounds. One-third of participants $(33.0 \%)$ reported having suffered from a mental illness at a point in their lifetime; only half of them $(50.7 \%)$ ever contacted a mental health professional and $21.1 \%$ of them took prescribed psychotropic medications. Almost half of the sample $(42.2 \%)$ reported having a family member with a mental illness.

The mean scores on the RIBS and PDDS were 15.26 \pm 4.75 and $32.25 \pm 2.70$, respectively. Almost two-thirds of participants $(59.3 \%)$ had high scores on the RIBS and were categorized as having positive views of individuals with mental illness. Close to $90 \%$ of participants were found to have high perceived stigma as per the PDDS.

More information about the sociodemographic characteristics of participants, including their interactions with individuals who have a mental health problem, is provided in Table 1.

\section{Bivariate Analyses of Correlates of High Scores on the RIBS and PDDS}

Table 2 shows the bivariate analyses of correlates of high scores on the RIBS and PDDS. Participants with positive views and attitudes, as detected by the RIBS, were more likely to be medical students than nurses or medical doctors $(p=0.001)$. Moreover, they were more likely to have previously sought help from a mental health professional $(p=0.004)$, to have had a history of mental health issues $(p=0.000)$, and to have had previous interactions with people with mental health problems $(p=0.000)$.

Looking into public stigma and discrimination related to mental illness as per the PDDS, we found only one significant correlate: participants without a family history of mental health problems had significantly higher perceived stigma than those with a positive family history $(p=0.025)$.

\section{Logistic Regression Analysis of Predictors of High Scores on the RIBS}

We conducted a multivariate stepwise logistic regression analysis to identify predictors of positive attitudes towards individuals with mental illness in the total sample. The overall model was statistically significant $(p=0.002)$. Participants who had a high score on RIBS were more likely to be younger than 25 years of age $(\mathrm{OR}=1.869$; $\mathrm{CI}[1.078-3.240] ; p=0.026)$, to have a history of mental illness $(\mathrm{OR}=2.657$; CI $[1.402$ 5.036]; $p=0.003$ ), and to interact with individuals with a psychiatric disorder $(\mathrm{OR}=2.287$; CI [1.092-4.789]; $p=0.028)$. Gender and seeking mental health professionals did not achieve significance in the model. Alternatively, our logistic analysis specific to respondents from the hospital yielded a model that was not statistically significant $(p=0.644)$. 
Table 1. Sociodemographic and personal data of participants

\begin{tabular}{|c|c|c|}
\hline \multicolumn{2}{|l|}{ Variable of interest } & \multirow{2}{*}{$\frac{\text { Percentage }(\boldsymbol{n})}{51.5(139)}$} \\
\hline Age & $18-25$ & \\
\hline & $26-30$ & $18.1(49)$ \\
\hline & $31-40$ & $17.8(48)$ \\
\hline & $41-50$ & $4.4(12)$ \\
\hline & $51-60$ & $5.2(14)$ \\
\hline & $>60$ & $2.6(7)$ \\
\hline \multirow[t]{3}{*}{ Gender } & Male & $36.7(99)$ \\
\hline & Female & $62.2(168)$ \\
\hline & Non-binary & $.7(2)$ \\
\hline \multirow[t]{2}{*}{ Nationality } & Lebanese & $87.0(235)$ \\
\hline & Non-Lebanese & $12.2(33)$ \\
\hline \multirow[t]{8}{*}{ Role at the American University of Beirut } & Faculty member at the university & $5.9(16)$ \\
\hline & Faculty member at the hospital & $1.9(5)$ \\
\hline & Staff at the university & $4.4(12)$ \\
\hline & Staff at the hospital & $6.7(18)$ \\
\hline & Nurse at the hospital & $12.2(33)$ \\
\hline & Resident at the hospital & $11.9(32)$ \\
\hline & Non-medical student at the university & $17.4(47)$ \\
\hline & Medical student at the university & $39.3(106)$ \\
\hline \multirow[t]{2}{*}{ Have you ever suffered from a mental illness? } & Yes & $33.0(89)$ \\
\hline & No & $64.1(173)$ \\
\hline \multirow[t]{2}{*}{ Have you ever been in contact with a mental health professional? } & Yes & $50.7(137)$ \\
\hline & No & $48.9(132)$ \\
\hline \multirow[t]{2}{*}{ Have you ever taken a prescribed psychotropic medication? } & Yes & $21.1(57)$ \\
\hline & No & $78.5(212)$ \\
\hline \multirow[t]{2}{*}{ Do you have a family member with a mental illness? } & Yes & $42.2(114)$ \\
\hline & No & $56.3(152)$ \\
\hline \multirow{2}{*}{$\begin{array}{l}\text { How comfortable would you feel to disclose your } \\
\text { mental health problems to family and friends? }\end{array}$} & Comfortable & $64.4(174)$ \\
\hline & Uncomfortable & $33.3(90)$ \\
\hline \multirow{2}{*}{$\begin{array}{l}\text { How comfortable would you feel to disclose your } \\
\text { mental health problems to coworkers and colleagues? }\end{array}$} & Comfortable & $27.4(74)$ \\
\hline & Uncomfortable & $70.4(190)$ \\
\hline \multirow{3}{*}{$\begin{array}{l}\text { Are you currently living with, or have you ever lived with, s } \\
\text { omeone with a mental health problem? }\end{array}$} & Yes & $38.1(103)$ \\
\hline & No & $55.2(149)$ \\
\hline & Don’t know & $6.7(18)$ \\
\hline \multirow{3}{*}{$\begin{array}{l}\text { Are you currently working with, or have you ever worked } \\
\text { with, someone with a mental health problem? }\end{array}$} & Yes & $42.6(115)$ \\
\hline & No & $55.2(149)$ \\
\hline & Don’t know & $6.7(18)$ \\
\hline \multirow[t]{3}{*}{ Do you currently have, or have you ever had, a neighbor with a mental health problem? } & Yes & $28.1(76)$ \\
\hline & No & $42.6(115)$ \\
\hline & Don’t know & $29.3(79)$ \\
\hline \multirow[t]{3}{*}{ Do you currently have, or have you ever had, a close friend with a mental health problem? } & Yes & $64.8(175)$ \\
\hline & No & $30.4(82)$ \\
\hline & Don’t know & $4.8(13)$ \\
\hline
\end{tabular}

The total number of respondents per each question is 270 ; the "prefer not to disclose" responses were not reported in the table.

\section{Readiness of Doctors to Engage in Collaborative Mental Health Care}

The majority of respondents who participated in this subsection survey had a positive attitude towards collaborating with the mental health team, as detailed in Table 3.

\section{Discussion}

To the best of our knowledge, this is the first study that assesses stigmatizing behaviors and perceived stigma towards mental illness in an academic and hospital setting in Lebanon.
Our results show that a high proportion of participants displayed mental health stigma-related behaviors and a striking majority of them had a high level of perceived stigma.

These results parallel those of a recent national study showing high prevalence of stigmatizing behaviors and attitudes towards mental illness in a sample of Lebanese citizens [10]. Similar findings were noted in specific local subgroups of students [8] and religious figures [9]. In general, stigmatizing attitudes have been noted in the Arab world and were found to be associated with a limited understanding of the nature of mental illness [15]. In a recent systematic review, a majority of the 33 included articles reported Arab populations as having a negative portrayal of mental illness and endorsing 
Table 2. Bivariate analysis of RIBS and PDDS. Bold values denote statistical significance at the $p<0.05$ level

\begin{tabular}{|c|c|c|c|c|c|c|c|}
\hline \multirow[t]{2}{*}{ Variable of interest } & & \multicolumn{2}{|l|}{ RIBS score } & \multirow[t]{2}{*}{$p$-value } & \multicolumn{2}{|l|}{ PDDS score } & \multirow[t]{2}{*}{$p$-value } \\
\hline & & Low & High & & Low & High & \\
\hline Gender & $\begin{array}{l}\text { Female } \\
\text { Male }\end{array}$ & $\begin{array}{l}66(39.3 \%) \\
42(42.4 \%)\end{array}$ & $\begin{array}{l}102(60.7 \%) \\
57(57.6 \%)\end{array}$ & .614 & $\begin{array}{l}13(7.7 \%) \\
13(13.1 \%)\end{array}$ & $\begin{array}{l}155(92.3 \%) \\
86(86.9 \%)\end{array}$ & .151 \\
\hline Nationality & $\begin{array}{l}\text { Lebanese } \\
\text { Non-Lebanese }\end{array}$ & $\begin{array}{l}95(40.4 \%) \\
13(39.4 \%)\end{array}$ & $\begin{array}{l}140(59.6 \%) \\
20(60.6 \%)\end{array}$ & .841 & $\begin{array}{l}24(10.2 \%) \\
3(9.1 \%)\end{array}$ & $\begin{array}{l}211(89.8 \%) \\
30(90.9 \%)\end{array}$ & .841 \\
\hline Institutional body & $\begin{array}{l}\text { University } \\
\text { Hospital }\end{array}$ & $\begin{array}{l}36(48.0 \%) \\
73(37.6 \%)\end{array}$ & $\begin{array}{l}39(52.0 \%) \\
121(62.4 \%)\end{array}$ & .120 & $\begin{array}{l}12(16.0 \%) \\
16(8.2 \%)\end{array}$ & $\begin{array}{l}63(84.0 \%) \\
178(91.8 \%)\end{array}$ & .062 \\
\hline Role at the hospital & $\begin{array}{l}\text { Medical student } \\
\text { Nurse/doctor }^{\mathrm{a}}\end{array}$ & $\begin{array}{l}27(25.5 \%) \\
34(49.3 \%)\end{array}$ & $\begin{array}{l}79(74.5 \%) \\
35(50.7 \%)\end{array}$ & .001 & $\begin{array}{l}8(7.5 \%) \\
5(7.2 \%)\end{array}$ & $\begin{array}{l}98(92.5 \%) \\
64(92.8 \%)\end{array}$ & .941 \\
\hline Sought help ${ }^{\mathrm{b}}$ & $\begin{array}{l}\text { No } \\
\text { Yes }\end{array}$ & $\begin{array}{l}62(50.0 \%) \\
48(32.9 \%)\end{array}$ & $\begin{array}{l}62(50.0 \%) \\
98(67.1 \%)\end{array}$ & .004 & $\begin{array}{l}10(8.1 \%) \\
28(10.4 \%)\end{array}$ & $\begin{array}{l}114(91.9 \%) \\
242(89.6 \%)\end{array}$ & .252 \\
\hline Mental health history & $\begin{array}{l}\text { No } \\
\text { Yes }\end{array}$ & $\begin{array}{l}90(52.0 \%) \\
19(21.3 \%)\end{array}$ & $\begin{array}{l}83(48.0 \%) \\
70(78.7 \%)\end{array}$ & .000 & $\begin{array}{l}20(11.6 \%) \\
8(9.0 \%)\end{array}$ & $\begin{array}{l}153(88.4 \%) \\
81(91.0 \%)\end{array}$ & .523 \\
\hline Family mental health history & $\begin{array}{l}\text { No } \\
\text { Yes }\end{array}$ & $\begin{array}{l}70(46.1 \%) \\
37(32.5 \%)\end{array}$ & $\begin{array}{l}82(53.9 \%) \\
77(67.5 \%)\end{array}$ & .419 & $\begin{array}{l}14(9.2 \%) \\
14(12.3 \%)\end{array}$ & $\begin{array}{l}138(90.8 \%) \\
100(87.7 \%)\end{array}$ & .025 \\
\hline Social interaction ${ }^{\mathrm{c}}$ & $\begin{array}{l}\text { No } \\
\text { Yes }\end{array}$ & $\begin{array}{l}27(65.9 \%) \\
83(36.2 \%)\end{array}$ & $\begin{array}{l}14(34.1 \%) \\
146(63.8 \%)\end{array}$ & .000 & $\begin{array}{l}6(14.6 \%) \\
22(9.6 \%)\end{array}$ & $\begin{array}{l}35(85.4 \%) \\
207(85.5 \%)\end{array}$ & .331 \\
\hline
\end{tabular}

a "Doctor" includes an attending or resident.

${ }^{\mathrm{b}}$ Answered yes to at least one of the following: Have you ever been in contact with a mental health professional? Have you ever taken a prescribed psychotropic medication?

${ }^{\mathrm{c}}$ Answered yes to at least one of the following: Are you currently living with, or have you ever lived with, someone with a mental health problem? Are you currently working with, or have you ever worked with, someone with a mental health problem? Do you currently have, or have you ever had, a neighbor with a mental health problem? Do you currently have, or have you ever had, a close friend with a mental health problem?

stigmatizing beliefs about the origins and causes of mental illness. Those beliefs were heavily influenced by religious teachings, cultural stereotypes, and family traditions [5].

When further looking into the results, medical students at the American University of Beirut were found to have fewer stigmatizing behaviors than doctors and nurses. This has been previously reported in the literature. A study in The Czech Republic showed that teachers had a greater prevalence of stigmatizing attitudes and behaviors towards psychiatric disorders than medical students [16]. Research has shown that the updated medical curricula and psychiatric clerkships have helped decrease stigma towards mental illness [17]. These results are, however, not always replicated [18]. Such inconsistent findings might be associated with certain pedagogical factors that affect one's learning experiences [19]. Additionally, recent studies assessing university students in

Table 3. Readiness of doctors to engage in collaborative mental health care as per DACC-MH.

\begin{tabular}{|c|c|c|c|c|c|}
\hline \multirow[t]{2}{*}{ Item of the DACC-MH } & \multicolumn{5}{|c|}{ Agreement percentage (n) } \\
\hline & Resident & Nurse & Medical student & Attending & Total \\
\hline I would welcome more contact with psychiatrists. & $100(28)$ & $100(12)$ & $94.1(16)$ & $100(4)$ & $98.4(60)$ \\
\hline I would like more help in providing psychological and social care. & $96.6(28)$ & $91.7(11)$ & $94.1(16)$ & $100(4)$ & $95.2(59)$ \\
\hline $\begin{array}{l}\text { I would like to know more about what psychiatrists } \\
\text { have to offer in the management of medical or surgical patients. }\end{array}$ & $100(29)$ & $91.7(11)$ & $93.8(15)$ & $100(4)$ & $96.7(59)$ \\
\hline I would like more contact with the psychiatric service. & $96.4(27)$ & $90.9(10)$ & $75(12)$ & $100(4)$ & $89.8(53)$ \\
\hline $\begin{array}{l}\text { Management of emotional problems is an important } \\
\text { part of my care of chronic patients. }\end{array}$ & $100(27)$ & $100(12)$ & $100(17)$ & $100(4)$ & $100(60)$ \\
\hline $\begin{array}{l}\text { When psychological factors are an important cause } \\
\text { of the problem, I confine myself to physical assessment. }\end{array}$ & $40.9(9)$ & $54.5(6)$ & $66.7(10)$ & $75(3)$ & $53.8(28)$ \\
\hline $\begin{array}{l}\text { Hospital doctors should be able to use psychological } \\
\text { methods like discussion of anxiety or problems. }\end{array}$ & $96.7(29)$ & $100(12)$ & $87.5(14)$ & $100(4)$ & $95.2(59)$ \\
\hline Hospital doctors are not responsible for emotional care of patients. & $86.7(26)$ & $58.3(7)$ & $0(0)$ & $25(1)$ & $53.1(34)$ \\
\hline
\end{tabular}


Lebanon [8] and other Arab countries [20] showed high stigmatizing behaviors and misconceptions about mental illness, leading to reluctance in seeking professional help.

Alternatively, the high level of perceived stigma among participating medical professionals is similar to that described in the Arab healthcare setting [21]. Generally speaking, when dealing with mental illness, most Arab families prefer to consult with a family physician. However, several barriers for optimal delivery of mental health services at the primary care level were described. These include the overwhelmingly negative attitudes of Arab physicians towards individuals with mental illness and the consideration of their care as too specialized and challenging [21]. If such discrimination is experienced at the very first help-seeking step, therefore, chances for future mental health referral and treatment might be hindered. Conversely, if stigma in the primary care setting is less prevalent, help-seeking, referral, treatment, and recovery can substantially increase [21]. In our sample of medical professionals, surprisingly, despite the high levels of perceived stigma, a high readiness to collaborate with mental health services was noted. These findings are similar to another regional study employing the DACC-MH, also showing that physicians maintained positive attitudes towards requesting psychiatric consultations [22]. Our results are possibly a reflection of the high level of mental health education provided at our academic center, along with the typically implemented interdisciplinary approach for patients' care that involves both a psychiatrist and a psychologist.

Individuals with a history of mental illness and those seeking professional help were noted to have fewer stigmatizing behaviors than those without mental illness or not following up. This comes in agreement with an analysis from 14 European countries showing that those with mental illness living in a setting with less stigmatizing attitudes, higher rates of treatment utilization, and better-perceived access to information had lower rates of self-stigma and perceived discrimination [23].

Another important finding is the high level of perceived stigma among participants. Perceived stigma refers to one's belief that others perceive an individual as socially unacceptable [24]. This finding reflects societal views of mental health stigma, as questions are addressed following the phrasing "most people would." In other words, despite the majority of participants having low stigmatizing behaviors, most found that mental health is negatively perceived in Lebanon.

Moreover, results revealed that individuals with a family history of mental illness had less perceived stigma as opposed to their counterparts. In fact, some studies have shown that stigma towards mental illness is lower among people who were familiar with it $[25,26]$. However, despite this significant difference in our results, the level of perceived stigma was overall elevated in both groups, regardless of family history. A diagnosis of mental illness carries a stigma that affects family members worldwide [27], particularly in the Arab region where having a psychiatric diagnosis remains a cultural taboo and increases the risk of social rejection. Along the same lines, a multi-site study found a greater occurrence of shame and family embarrassment when a close relative is affected by mental illness [28]. Families are often blamed for their relatives' illness and criticized for housing potentially dangerous relatives [26]. This concept translates into "stigmaby-association" which affects everyone surrounding the individual with mental illness [1]. "Stigma-by-association" represents fear, loss, embarrassment, disgrace, isolation, anger, inability to cope, and eventually helplessness [29]. Unfortunately, strategies that some families employ to cope with this burden, such as "concealing" or "secrecy," can often reinforce stigma [30].

The impact of stigma on affected individuals includes not only low self-esteem and social isolation but also a more complicated illness trajectory and, eventually, poor quality of life [31]. This heightened stigma comes on top of a burdened mental health system in the Arab world [32]. Lebanon has one of the highest provisions of psychiatric services in the Eastern Mediterranean Region, with a median of 3 mental health professionals per 100,000 population [33]. Yet, this remains insufficient due to the limited facilities and an overall shortage of associated workforce in the country [33]. Additionally, the Lebanese health system still lacks a mental health law and a national mental health policy [32]. And despite the high prevalence of psychiatric disorders within the Lebanese population, mental illness remains considerably stigmatized [34].

Therefore, it becomes imperative to establish large-scale and targeted strategies that help decrease stigma towards mental illness. One proven effective approach is mental health education for both medical professionals and students. At this level, mental health literacy campaigns, which include wholeof-community campaigns, information websites, Mental Health First Aid training, and other interventions in educational settings [35], have been pivotal; they improve knowledge, attitudes, and help-seeking behaviors [36]. Getting an early start and educating the youth using school-based curricula should be considered, as youth are more likely to seek treatment when assigned specific mental health courses [37]. Therefore, appropriate training modules and effective learning curricula that foster a comfortable anti-stigma environment should be provided for both medical and non-medical students. A more general avenue worth exploring is that of media outlets which may, at times, increase stigma by reinforcing common stereotypes [38]. As such, targeted media interventions, mass awareness campaigns, and social media can reduce stigmatizing attitudes [39], particularly when involving medical professionals. Finally, interactive interventions with individuals with mental illness can help dispel myths about psychiatric disorders [40]. 
Our study has several limitations. First, it has a crosssectional design and a small sample size. Further, we were not able to reach our target sample size in each subgroup, limiting the scope of the subgroup statistical analyses. Participants were recruited from one academic institution and its affiliated hospital and about $70 \%$ of the sample comprised medical personnel only. Also, individuals at the institution typically diverge from the general Lebanese population, particularly in terms of education level and socioeconomic status further restricting the generalizability of our results to the Lebanese community. As the study is based on self-reports, response bias cannot be excluded. Besides, our scales have not been linguistically nor culturally validated in Lebanon; we only provided the English version of the scales to the participants. This might limit the validity of our results; however, students, faculty, and staff in the American University of Beirut are required to be proficient in the English language. It is also worthy to note that the study was done before the COVID-19 pandemic and the Beirut Blast of August 04, 2020. After these events, Lebanon has witnessed a surge of mental health campaigns across various different media outlets, organized by the government, non-governmental organizations, and private institutions. Future studies should assess if these activities have helped increase awareness towards mental illness and reduced stigma among the population.

Our study shows a mixed pattern of stigmatizing behaviors and perceptions towards mental illness at a Lebanese academic institution and hospital. Our results are in accordance with national and regional findings. This highlights the need to promote mental health awareness in Lebanon. One such strategy might be to incorporate mental health education in all school curricula.

\section{Declarations}

Ethical Considerations The study received approval from the Institutional Review Board of the American University of Beirut.

Disclosures On behalf of all authors, the corresponding author states that there is no conflict of interest.

\section{References}

1. Goffman E. Stigma: notes on the management of spoiled identity: Englewood Cliffs NJ: Prentice Hall; 1963.

2. Link BG, Phelan JC. Conceptualizing stigma. Annu Rev Sociol. 2001;27(1):363-85.

3. Sheehan L, Nieweglowski K, Corrigan PW. Structures and types of stigma. In: Gaebel W, Roessler W, Sartorius N, editors. The stigma of mental illness - end of the story? Cham, Switzerland: Springer International Publishing; 2017. p. 43-82.
4. Krendl AC, Pescosolido BA. Countries and cultural differences in the stigma of mental illness: the east-west divide. J Cross-Cult Psychol. 2020;51(2):149-67.

5. Zolezzi M, Alamri M, Shaar S, Rainkie D. Stigma associated with mental illness and its treatment in the Arab culture: a systematic review. Int J Soc Psychiatry. 2018;64(6):597-609.

6. Dardas LA, Simmons LA. The stigma of mental illness in Arab families: a concept analysis. J Psychiatr Ment Health Nurs. 2015;22(9):668-79.

7. Youssef J, Deane FP. Factors influencing mental-health help-seeking in Arabic-speaking communities in Sydney, Australia. Ment Health Relig Cult. 2006;9(1):43-66.

8. Rayan A, Fawaz M. Cultural misconceptions and public stigma against mental illness among Lebanese university students. Perspect Psychiatr Care. 2018;54(2):258-65.

9. Aramouny C, Kerbage H, Richa N, Rouhana P, Richa S. Knowledge, attitudes, and beliefs of Catholic clerics' regarding mental health in Lebanon. J Relig Health. 2020;59(1):257-76.

10. Abi Doumit C, Haddad C, Sacre H, Salameh P, Akel M, Obeid S, et al. Knowledge, attitude and behaviors towards patients with mental illness: results from a national Lebanese study. PLoS One. 2019;14(9):e0222172.

11. Evans-Lacko S, Rose D, Little K, Flach C, Rhydderch D, Henderson C, et al. Development and psychometric properties of the reported and intended behaviour scale (RIBS): a stigma-related behaviour measure. Epidemiol Psychiatr Sci. 2011;20(3):263-71.

12. Bifftu BB, Dachew BA. Perceived stigma and associated factors among people with schizophrenia at Amanuel Mental Specialized Hospital, Addis Ababa, Ethiopia: a cross-sectional institution based study. Psychiatry J. 2014;2014:694565.

13. Thombs BD, Adeponle AB, Kirmayer LJ, Morgan JF. A brief scale to assess hospital doctors' attitudes toward collaborative care for mental health. Can J Psychiatr. 2010;55(4):264-7.

14. IBM Corp. Released 2013. IBM SPSS Statistics for Windows, Version 22.0. Armonk, NY: IBM Corp.

15. Abolfotouh MA, Almutairi AF, Almutairi Z, Salam M, Alhashem A, Adlan AA, et al. Attitudes toward mental illness, mentally ill persons, and help-seeking among the Saudi public and sociodemographic correlates. Psychol Res Behav Manag. 2019;12:45-54.

16. Janoušková M, Weissová A, Formánek T, Pasz J, Bankovská ML. Mental illness stigma among medical students and teachers. Int J Soc Psychiatry. 2017;63(8):744-51.

17. De Witt C, Smit I, Jordaan E, Koen L, Niehaus DJH, Botha U. The impact of a psychiatry clinical rotation on the attitude of South African final year medical students towards mental illness. BMC Med Educ. 2019;19(1):114.

18. Lyons Z, Janca A. Impact of a psychiatry clerkship on stigma, attitudes towards psychiatry, and psychiatry as a career choice. BMC Med Educ. 2015;15:34.

19. Dolmans DH, Wolfhagen IH, Heineman E, Scherpbier AJ. Factors adversely affecting student learning in the clinical learning environment: a student perspective. Educ Health (Abingdon). 2008;21(3): 32.

20. Vally Z, Cody BL, Albloshi MA, Alsheraifi SNM. Public stigma and attitudes toward psychological help-seeking in the United Arab Emirates: the mediational role of self-stigma. Perspect Psychiatr Care. 2018;54(4):571-9.

21. Merhej R. Stigma on mental illness in the Arab world: beyond the socio-cultural barriers. Int J Hum Rights Healthc. 2019;12(4):28598.

22. Hamdieh M, Banihashem S, Beyraghi N, Abbasinejad M, HaghRanjbar F. Physicians' attitudes toward integrating consultationliaison psychiatric services in four major general hospitals in Tehran. Gen Hosp Psychiatry. 2015;37(5):456-8. 
23. Evans-Lacko S, Brohan E, Mojtabai R, Thornicroft G. Association between public views of mental illness and self-stigma among individuals with mental illness in 14 European countries. Psychol Med. 2012;42(8):1741-52.

24. Latalova K, Kamaradova D, Prasko J. Perspectives on perceived stigma and self-stigma in adult male patients with depression. Neuropsychiatr Dis Treat. 2014;10:1399-405.

25. Dixon LB, Lucksted A, Medoff DR, Burland J, Stewart B, Lehman $\mathrm{AF}$, et al. Outcomes of a randomized study of a peer-taught Familyto-Family Education Program for mental illness. Psychiatr Serv. 2011;62(6):591-7.

26. Corrigan PW, Miller FE. Shame, blame, and contamination: a review of the impact of mental illness stigma on family members. J Ment Health. 2004;13(6):537-48.

27. Dalky HF. Mental illness stigma reduction interventions: review of intervention trials. West J Nurs Res. 2011;34(4):520-47.

28. Ahmedani BK, Kubiak SP, Kessler RC, de Graaf R, Alonso J, Bruffaerts R, et al. Embarrassment when illness strikes a close relative: a World Mental Health Survey Consortium Multi-Site Study. Psychol Med. 2013;43(10):2191-202.

29. Veltman A, Cameron J, Stewart DE. The experience of providing care to relatives with chronic mental illness. J Nerv Ment Dis. 2002;190(2):108-14.

30. Stengler-Wenzke K, Trosbach J, Dietrich S, Angermeyer MC. Experience of stigmatization by relatives of patients with obsessive compulsive disorder. Arch Psychiatr Nurs. 2004;18(3):88-96.

31. Holubova M, Prasko J, Ociskova M, Marackova M, Grambal A, Slepecky M. Self-stigma and quality of life in patients with depressive disorder: a cross-sectional study. Neuropsychiatr Dis Treat. 2016;12:2677-87.

32. Okasha A, Karam E, Okasha T. Mental health services in the Arab world. World Psychiatry. 2012;11(1):52-4.
33. El-Jardali F, Yehia F. K2P policy brief: securing access to quality mental health services in primary health care in Lebanon. Knowledge to Policy (K2P) Center, Beirut, Lebanon, 2014, p. 53.

34. Karam EG, Mneimneh ZN, Karam AN, Fayyad JA, Nasser SC, Chatterji S, et al. Prevalence and treatment of mental disorders in Lebanon: a national epidemiological survey. Lancet. 2006;367(9515):1000-6.

35. Jorm AF. Mental health literacy: empowering the community to take action for better mental health. Am Psychol. 2012;67(3): 231-43.

36. Wei Y, Hayden JA, Kutcher S, Zygmunt A, McGrath P. The effectiveness of school mental health literacy programs to address knowledge, attitudes and help seeking among youth. Early Interv Psychiatry. 2013;7(2):109-21.

37. Link BG, DuPont-Reyes MJ, Barkin K, Villatoro AP, Phelan JC, Painter K. A school-based intervention for mental illness stigma: a cluster randomized trial. Pediatrics. 2020;145(6):e20190780.

38. Maiorano A, Lasalvia A, Sampogna G, Pocai B, Ruggeri M, Henderson C. Reducing stigma in media professionals: is there room for improvement? Results from a systematic review. Can J Psychiatry. 2017;62(10):702-15.

39. Pirkis J, Rossetto A, Nicholas A, Ftanou M, Robinson J, Reavley N. Suicide prevention media campaigns: a systematic literature review. Health Commun. 2019;34(4):402-14.

40. Corrigan PW, Morris SB, Michaels PJ, Rafacz JD, Rüsch N. Challenging the public stigma of mental illness: a meta-analysis of outcome studies. Psychiatr Serv. 2012;63(10):963-73.

Publisher's Note Springer Nature remains neutral with regard to jurisdictional claims in published maps and institutional affiliations. 